Boston University School of Law

Scholarly Commons at Boston University School of Law

Faculty Scholarship

2001

The Managing Lawmaker in Cyberspace: A New Power Model

Tamar Frankel

Follow this and additional works at: https://scholarship.law.bu.edu/faculty_scholarship

Part of the Law Commons 


\section{BOSTON UNIVERSITY SCHOOL OF LAW}

Working Paper Series, Public LaW \& Legal Theory

Working PAPER No. 01-17

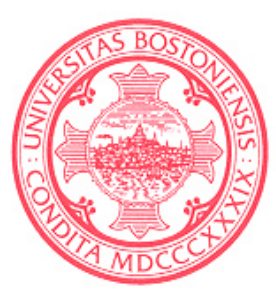

\section{The MANAgING LAWMAKER IN CYBERSPACE: A NeW POWER MOdEL}

TAMAR FRANKEL

This paper can be downloaded without charge at:

The Boston University School of Law Working Paper Series Index: http://www.bu.edu/law/faculty/papers

The Social Science Research Network Electronic Paper Collection:

$\underline{\text { http://papers.ssrn.com/abstract }=288544}$ 


\title{
The Managing Lawmaker in Cyberspace: A New Power Model
}

\author{
Tamar Frankel
}

\begin{abstract}
This paper is about the power of The Internet Corporation for Names and Numbers (ICANN). It examines how this power was created, augmented, strengthened, and reigned in. ICANN poses a puzzle. It is essentially an unregulated and undemocratic monopoly. Yet, ICANN's exercise of power has been fairly contained. Since ICANN is a monopoly, what prevents it from taking a far more high-handed and extensive ruling posture?

Even though at first blush my analogy is counterintuitive, I analogize ICANN to a managing lawmakers of market infrastructures, such as the New York Stock Exchange, while recognizing their differences. Unlike the Exchange, ICANN has close affinity to a political unit as well.

The emergence of ICANN, its staying power, and the limitations on the exercise of its power, can be partly explained by an analogy to the economic theory of "contestable markets." The theory deals with price. I equate price to power. High prices denote a high level of power. Low prices denote a lower level of power. In essence the theory suggests that under certain conditions a monopolist would charge low prices as if it operated in a competitive market. That is because higher prices will bring less efficient competitors into the market until prices fall and they will exit. This theory highlights a special "balance of power" and its restraining effect. I believe that a similar idea helps understand ICANN's environment

The paper notes that ICANN exercises "power in default." All the strong constituents seem to have agreed not to claim exclusive control over the Internet infrastructure. The paper discusses the bases for ICANN's continuous power: its constitutional documents, and contracts, which have become part of its constitution, and its role as mediator among Internet large stakeholders. ICANN has augmented its power by a stable and able management, and arguably maintained and strengthened its following by doing its share to support the stability of the Internet.

ICANN's rising power is demonstrated by the controversies concerning the country code Top Level Domain names (ccTLDs).

The paper concludes that ICANN's power is still being shaped. It could emerge along a market model, as a central catalyst for consensus building among parties with different interests. Alternatively, ICANN could also move towards a more regulatory model of consensus-based decision making. These decisions may then constitute precedents and mature into rules. Or ICANN can combine the two models to form a more structured market and more flexible regulatory body. The market model is likely to make experiment in the development of more than one root easier than the regulatory model. As the telephone experience has shown, the time may come for a multi-root cooperative Internet structure. Or we may face a technology that is today a mere twinkle in someone's eye.
\end{abstract}




\section{$\begin{array}{lllllllll} & \mathbf{R} & \mathbf{A} & \mathbf{F} & \mathbf{T}\end{array}$}

c. 2001. All rights

reserved. No part of

this paper may be

reproduced or cited

without the permission

of the author.

Essay

\section{The Managing Lawmaker in Cyberspace}

A New Power Model

Tamar Frankel

\section{INTRODUCTION}

This paper is about power - the ability to gain obedience, whether by commanding the admiration of followers, persuading of skeptics, or bestowing and withdrawing economic benefits. The purpose of this paper is to analyze how the power of The Internet Corporation for Names and Numbers (ICANN) was created, augmented, strengthened, and reigned in. Many controversies surround ICANN, including the very foundation of its existence - the need for a single root--its organizational structure and accountability, and the utterances and actions of its management.

The purpose of this paper is not to argue and prescribe but to describe and explain. Description, however, is rarely, if ever, neutral. Mine is no exception. I am biased in favor of the ICANN experiment. I hope it matures to become a model for a global organization - with a limited mission, grounded in a unique type of consensus, and operated in a special kind of balance of power environment.

ICANN manages some of the Internet's operational infrastructure and establishes some of its constitutive rules. ${ }^{1}$ Internet service providers depend on these rules to provide users with universal connectivity. I use the term management in a very broad sense. ICANN neither operates nor fully controls any of the actors that constitute the Internet's

\footnotetext{
- Tamar Frankel, Professor of Law, Boston University School of Law. I owe many of the clarifications in this paper to comments of David Johnson, Esq., Kenneth A. Cukier, Editor, Wall Street Journal, Asia, Hong Kong, and Professor Michael Meuer, Boston University Law School.

${ }^{1}$ ICANN plays a lesser role with respect to Internet Service Providers (ISPs). Large ISPs can decide whether to point at the ICANN root. They have no contractual obligation to follow ICANN's policies, or otherwise interact with ICANN except in connection with the allocation of IP blocks.
} 
infrastructure. It has, however, power, in varied degrees, to direct these actors. ${ }^{2}$ For lack of a better word, this is what I call "managing."

The inquiry is important because ICANN plays a role in the operation of the Internet. The inquiry is interesting because, like the Internet, ICANN has no precise analog. ${ }^{3}$ The inquiry is difficult because the location and identity of ICANN's power are murky, contradictory, and confusing. They are not easily generalized into a theory. Its power structure is fashioned after a private not for profit corporation, but it does not operate enterprises usually operated by such corporations, like museums or hospitals, or credit card organizations. Rather, it manages a unique type of a market.

The use of the market image for the Internet and its infrastructure sounds counterintuitive. More often, the image of ICANN is drawn from the store of political metaphors as a global government, and its users as citizens; a relationship among users, service providers and ICANN grounded in a "social contract." I find this metaphor inadequate and confusing. The market image is more helpful to understanding the ICANN phenomenon, its power and limitations on its power.

Markets and political units share some features. Both require an infrastructure. Both require an implicit agreement, a consensus, among most actors as to the fundamental "rules of the game." A "social contract" denotes an acceptable political or social regime governing many aspects of our lives. But markets affect our lives to the same, if not to a greater, extent. After all, food, shelter, and all we consume are found in the markets; our livelihood is earned in the markets. The distinction therefore is not in impact but perhaps in the enforcement power of political units as compared to markets. Political units have different enforcement mechanisms than the markets, and their infrastructures differ. As compared to political units, the objectives and coercive powers of the markets' infrastructure are far more limited. The New York Stock Exchange and broker dealers do not have the objectives nor the powers of the army and police.

Even though ICANN's objectives and powers have not yet been fully defined, I view its position as a market manager and lawmaker rather than a political unit. To call ICANN's foundation a "social contract" means to equate it to some sort of a government, regulating the impact of the Internet on peoples' lives, and to give its users the status of citizens. To call it a manager, lawmaker, or regulator of a market is to recognize that the objectives of its "social contract" are far more limited and its power is grounded in

\footnotetext{
${ }^{2}$ ICANN's power over the Internet Service providers (ISPs) is minimal, and depends on their consensus of using a single root. Its power over the registries of most ccTLDs is limited, but it can exert more pressure on registries of gTLDs. See part One sections 1,2 below.

3 Some international organizations, such as the International Olympic Commission and the Diamond Exchange have arisen not by the support of governments or laws but through the initiative of participants. Similar initiatives have given rise to national organizations, such as stock exchanges, trade organizations and professional associations. However, they differ from ICANN in a number of important aspects. They were organized directly by the interested parties, their purpose of organization was usually quite specific, such as Olympic games, or for the purpose of regulating their members, and most national organizations are regulated by governments, as backup regulators.
} 
acceptable technical and business regimes, rather than social and political regimes. More importantly, the "social contract" denotes coercive state power; ICANN, has little such power, if any. Therefore, I would stick to my market model. Because the Internet affects social interaction I will admit, however, to its political undertones. ${ }^{4}$

I use the term market in a broader sense than the sense to signify more than exchange of things measured by money or economic values. The Internet and its infrastructure accommodate exchanges in the sense of "crossing points, swaps, tradeoffs, and interchanges" among people (and machines). Significantly, a synonym of the word "interchange" includes "conversing." Thus, exchange on and through the Internet may involve sending and receiving information, but does not require simultaneous contact, or reciprocity, or a common denominator, such as money or another precise measure (e.g., beads). The market image hlps analyze the interchange of power and reciprocity exercised by and over ICANN, even though they are imprecise and hard to measure.

ICANN can be analogized to the New York Stock Exchange. Both institutions act as a focal point, and as a synthesizer among the disparate parts that constitute the infrastructure of the system. Like the Exchange, ICANN combines management in a broad sense of the term, and lawmaking functions. Like the Exchange, it has a board of directors, officers and employees who carry out its institutional functions. Like them, these actors are in the public eye, for all to see and judge. Like the Exchange, ICANN affects the actors that constitute the infrastructure of the market - the domain names registries, the registrars and influences to some extent the Internet Service Providers (ISPs). Like the actors in the securities markets (the underwriters, brokers, dealers and custodians, among others), Internet actors operate independently, some for profit and some not for profit. Like the New York brokers who gathered on the Curb at the beginning of this century, ICANN's creators started by interacting and searching for a network communication unlimited by subject matter and purposes.

However, and perhaps because of ICANN's political aspects, the Internet market and ICANN differ in significant ways from the securities markets and their managing lawmakers. Unlike the actors in the securities market neither the actors constituting the infrastructure of the Internet nor ICANN are regulated under the laws of a country, enforced by government agencies. ${ }^{5}$ Rather, the regulation and legal foundation of these actors and the accountability of ICANN to a "higher authority" are unclear. Even the authority of a "higher authority" such as the Department of Commerce is subject to queries. Moreover, ICANN's may be distinguished from the New York Stock Exchange because it functions partly as a policy setting institution, partly as a platform for

${ }^{4}$ I do not analogize ICANN to the United Nations or its organizations, first because the membership is usually political units, while ICANN was explicitly designed to exclude the control, though not the influence, of such unites. In addition, the United Nations' decisions can be backed by force, while it is doubtful whether ICANN's will ever have such a backing. See Nancy C.M. Hartsock, Money, Sex, and Power ch. 3 (1983) (dealing with economic markets, noting the disparities among the actors, and arguing that the market model legitimizes domination by the strong actors over the weaker actors).

${ }^{5}$ ICANN is a not for profit corporation incorporated under the Laws of California. However, the regulatory scope of both laws and enforcers of the laws is very limited. 
negotiation and mediation. ICANN has not yet reached maturity, and is likely to function in a state of flexible adjustment for sometime to come.

ICANN poses a puzzle. It is essentially an unregulated and undemocratic monopoly. Yet, while it is strengthening its power, ICANN's exercise of power has been fairly contained. Since ICANN is a monopoly, what prevents it from taking a far more high-handed and extensive ruling posture?

The emergence of ICANN, its staying power, and the limitations on the exercise of its power, can be partly explained by an analogy to the economic theory of "contestable markets." 6 The theory deals with price. I equate price to power. High prices denote a high level of power. Low prices denote a lower level of power. I will first describe the theory and then apply it to ICANN. The theory of contestable markets suggests that in some cases a monopolist or an oligopoly will charge the low price it would have charged had the market been competitive. These are the cases in which the monopolist is more efficient than its competitors, and can therefore sell or service at lower prices. At these prices, the less efficient competitors would not enter the market. For example, if one airline provides an optimal service between two towns (e.g., twice a week), and charges a price that allows it minimal profits, no competing airline will choose the same route.

Yet the monopolist will not raise the prices in contestable markets. In these markets, entry costs for potential competitors would not be higher than the entry costs for

${ }^{6}$ William J. Baumol, John C. Panzar and Robert D. Willig, Contestable Markets and The Theory of Industry Structure 5 (1982) ("We define a perfectly contestable market as one that is accessible to potential entrants and has the following two properties: First, the potential entrants can, without restriction, serve the same market demands and use the same productive techniques as those available to the incumbent firms. Thus, there are not entry barriers in the sense of the term used by Stigler. Second, the potential entrants evaluate the profitability of entry at the incumbent firms' pre-entry prices. That is, although the potential entrants recognize that an expansion of industry outputs leads to lower prices - in accord with the market demand curves - the entrants nevertheless assume that if they undercut incumbents' prices they can sell as much of the corresponding good as the quantity demanded by the market at their own prices"). Id. ("Stigler defines an entry barrier to be present when the potential entrants face costs greater than those incurred" by the incumbent).

7 One such example is traditional securities underwriting, which involved high risks and required very high investment and a distribution system. Smaller broker dealers did not enter this market because they could not compete with the very large underwriters on price and reliable performance. Among the underwriters there exists an apex structure. In 1983 the structure was predicted to continue, and it seems in 2001 that it has. See Samuel L. Hays III, A Michael Spence and David Van Praag Marks, Competition in the Investment Banking Industry 72-3, 76 (1982); id. at 78 (noting the research that suggests that "investment banking has long tended to assume a pyramidal competitive structure, with a few preeminent firms providing leadership in both financing and collateral services" and a tendency towards increased concentration. Nonetheless, the authors argue that this structure "masks a competitive structure" because the markets are segmented. . . certain types of clients and industries tend to gravitate towards "certain types of investment bankers). William J. Baumol, John C. Panzar and Robert D. Willig, Contestable Markets and The Theory of Industry Structure 7 (1982) (stating the airline industry as an example). 
the monopolist. ${ }^{8}$ For example, the cost of airplanes for the two airlines will be close, if not identical. In addition, the exit costs for competitors would be zero or close to zero. For example, an airline can exit a route with little cost by redirecting its planes to another route. Thus, the theory predicts that competitors will not enter the market only so long as they cannot afford to charge the monopolist's low prices. If, however, the monopolist charges higher prices, competitors will enter the market to offer the same service at the same prices or lower. When prices fall, these competitors will pocket their profits and exit the markets. Under this theory, the "potential or threatened competition of possible new competitors" presents a great constraining force. Potential competition will "extend the beneficent sway of the invisible hand" that leads the market.

The theory of contestable markets has led to the deregulation of the airlines, among others. Deregulation, however, demonstrated the flaws in the theory's predictions. ${ }^{9}$ The "correct" monopolistic or competitive price absent actual competition is controversial. Entry barriers defined as "sunken costs" are difficult to determine. It was discovered that exit involves transaction costs. Further, there is a price lag that provides insufficient after-entry profits for the entering competitors during the "hit-and-run" period. ${ }^{10}$ All these issues require correction, but judicial or government correction increases costs, ${ }^{11}$ and small corrections may result in far larger deviations. Nonetheless, this theory is helpful to explain the power market in which ICANN operates. Thus, application of the theory is far from perfect. Yet it is very useful.

The theory of contestable markets highlights a special "balance of power" and its restraining effect. I believe that a similar idea of a contestable market helps understand

\footnotetext{
${ }^{8}$ William J. Baumol, John C. Panzar and Robert D. Willig, Contestable Markets and The Theory of Industry Structure 7 (1982) (stating the airline industry as an example).

9 William B Tye, The Theory of Contestable Markets (1990) (listing a number of flaws in the theory).

10 Also, the theory did not take account of potential entrants, hovering in the background, who do not suffer from a pricing lag and are still "free to contest the entrant's excess profits ... [They] can eliminate those excess profits with the same competitive advantage. . William B Tye, The Theory of Contestable Markets 119 (1990) ("In many applications of the theory . . p perfectly contestable markets did not serve as the promised benchmark for measuring departures from the welfare optimum. . . Movements towards perfect contestability were believed to deprive incumbents of the sunk costs, cross subsidies, and other barriers to entry and price competition believed needed for firm viability and sustainability and to give full latitude to welfareenhancing price discrimination"); id at 120, 124 (1990) ("The principal difficulty is to achieve the proper balance of threat [of competitors' entry] and defense [by the incumbent]. Note that the discipline of constenstability requires that entrants threaten incumbents with sufficient credibility to eliminate excess profits. But if incumbents always have the same postentry competitive advantage as entrants, they could via the same logic immediately deny the entrants postentry excess profits that are necessary to elicit entry. The assumption of a pricing lag for incumbents is a somewhat arbitrary attempt to impose the necessary asymmetry between incumbent and entrant in the postentry world. But we have seen that this handicap is too strong when the incumbent prices above marginal cost because contestable suppliers of either perfect or imperfect substitutes can use it to diver business from the incumbent at a profit during the hit-and-run period."
}

${ }^{11}$ Id at 125 
ICANN's environment To be sure, while its institutional structure is still evolving, ICANN's existence and activities are based on a consensus of numerous power holders. More importantly, the large ISPs consensus to use a single root provides the foundation of ICANN's power. Most importantly, the tugging pressure of "path dependence" in the case of ICANN is very great. It costs to change legacy-systems. A move by some and not by other participants of the infrastructure may endanger the universality and integrity of the Internet. Even a slight move may generate a slippery slope towards disorder and unpredictability. The beneficent principle of "the devil you know" engenders an almost knee jerk reaction in this case. Nonetheless, I believe that the need for one guiding hand - a natural monopoly, on the one hand, and the ability of some players to overthrow ICANN or particular actions of ICANN, as illuminated by the theory of contestable markets, limit ICANN's exercise of power.

Part One of the Essay briefly describes the basic structure of the Internet naming and numbering system, relevant to ICANN's power. Part Two examines ICANN's initial source of power and explains it as power by default. All power holders and strong constituents seem to have agreed not to claim exclusive control over the Internet infrastructure. They may have recognized that none would consent to exclusive control over the infrastructure by any of the others. They may have doubted the efficiency of international bodies' regulation. ICANN's power derives from these agreements and doubts.

Part Three of the Essay discusses the bases for ICANN's continuous power: its constitutional documents, and contracts, which have become part of its constitution, and its role as mediator among Internet large stakeholders. ICANN has augmented its power through a stable and able management, especially capable service that prepares its contracts, steers it through the turbulent waters of complex international and national laws, supervises its statements, and negotiates on its behalf. Arguably, ICANN's has maintained and strengthened its following by doing its share to support the stability of the Internet (standardizing the infrastructure, allocating rights to Internet services, for example, allocating the valuable right to operate Top Level Domain Names, and establishing the underlying policies). This prime directive that ICANN follows, is of concern to almost everyone in the United States and abroad.

Part Four deals with ICANN's rising power and its boundaries, demonstrated by the controversies concerning the country code Top Level Domain names (ccTLDs). Part Five examines the boundaries of ICANN's power under contestable markets theory. This theory may explain why and how ICANN's monopoly power is reigned-in by the invisible hand of its numerous potential competitors. Many of ICANN's proposed activities are first aired among its strong powerful competitors such as numerous governments and large business interests. Upon a negative reaction, for example, congressional reaction in the United States, these proposals may not be pursued.

I conclude that ICANN's power is still being shaped. It could emerge along a market model, as a central catalyst for consensus building among parties with different interests. Alternatively, ICANN could also move towards a more regulatory model of consensus-based decision making. These decisions may then constitute precedents and mature into rules. Or ICANN can combine the two models to form a more structured market and more flexible regulatory body. The market model is likely to make 
experiment in the development of more than one root easier than the regulatory model. As the telephone experience has shown, the time may come for a multi-root cooperative Internet structure. Or we may face a technology that is today a mere twinkle in someone's eye.

\section{PART ONE. THE BASIC STRUCTURE OF THE NAMING AND NUMBERING SYSTEMS}

1. The Internet requires an infrastructure. As everyone knows, the Internet can be viewed as a network of networks free of central control and led by an "invisible hand." That is true to an extent, just as markets can be described as interactions among individuals and groups free of central control, led by an "invisible hand." Both systems, however, cannot function without an infrastructure. ${ }^{12}$ Put in biblical terms, without a common language both systems can become a dysfunctional Tower of Babylon. The Internet network requires that each receiver of messages will have a unique one-of-a-kind designation, and that each computer will have a unique number so that the "packages" of information will reach their destination. It requires that transmissions be governed by acceptable protocols. If receivers or spaces do not have unique designations and if the actors serving as the infrastructure do not follow the protocols, messages will miss their correct destinations. The Internet will become the Tower of Babylon. ${ }^{13}$

2. The feudal structure of the naming and numbering system. With a view to preventing chaos and ensuring stability, the Internet naming and numbering system was designed in a hierarchical mode. Each level contains a signifier, under which names and numbers within its sphere of influence are recorded. The single root or dot (.) is in fact a database for two letter country code domain names (ccTLDs) such as .uk. (United Kingdom), .fr (France). The root zone contains also generic top level domain names (gTLDs), such as .com, .org., .gov, .edu. ${ }^{14}$ That ensures, for example, that no other .edu exists. Under the .edu umbrella Boston University, Massachusetts Institute of Technology and other educational institutions are listed. No other Boston University can be listed. Under the name of each institution other names can be listed and managed, such as, tfrankel.

\footnotetext{
${ }^{12}$ See Tamar Frankel, Essay, The Legal Infrastructure of Markets: The Role of Contract and Property law, 73 B.U.L. Rev. 389 (1993).

${ }^{13}$ Internet Architecture Board (May 2000) IAB Technical Comment on the Unique DNS Root. (information for the Internet community emphasizing that the current one root should remain intact to avoid confusion); James Middleton, vnunet.com. EbusinessAlternative Domains Challenge ICANN (June 7, 2001) (noting "rogue domains" and that "ICANN plans to set up an oversight panel to take a firm stance against the alternative movement, claiming that there are 'solid technical grounds for a single authoritative root.'" The report describes the arguments and explanations for the emergence of these rogue alternative roots)). See also The Domain Name System: A Non-Technical Explanation - Why Universal Resolvability Is Important, http://www.internic.net/faqs/authoritative-dns-html.

14 J. Postel, ISI ( March 1994) Domain Name System Structure and Delegation (Describing the domain name system). On the arguments on whether new gTLDs should be added see http://www.icann.org/dnso/wgc-report-21mar)).htm Report (Part One) of Working Group C (New gTLDs) Presented to Names Council (21 March 2000); http://www.icann.org/dnso/wgcsupp-report-17apr00.htm Supplemental Report to Names Council Concerning Working Group C (17 April 2000); http://wwww.icann.org/dnso/gtld-topic-20apr00.htm Consideration of Introducing New Generic Top-Level Domains (20 April 2000)
} 
There is a general belief that the inter-connectivity of the Internet depends on the integrity and maintenance of this hierarchical structure, and that unless the message senders and transferors comply with the same rules, or protocols, confusion will reign. Hence, like market standards of weights and measures and prohibitions on fraud, the Internet is governed by structure and protocols. ${ }^{15}$

The intermediaries that form the Internet infrastructure are the Internet Service Providers (ISPs), registries, and registrars. Each registry registers and manages the database of the names under its unmbrella in the pyramid. Thus, the root registry registers the country code Top Level Domain Names (ccTLDs) and generic Top Level Domain Names (gTLDs); registries public the zone files of ccTLDs and gTLDs. Registrars enter the registration contracts in certain gTLDs. ISPs receive and transfer messages usually to other ISPs and through them to the final destination. ${ }^{16}$ The current practice among the large ISPs is to follow the single root structure.

3. The power of bestowing Internet names and numbers. An Internet name differs in value and function from a name in real space. A name is the spark that breathes life and very existence on the Internet. The loss of a name on the Internet is death without a trace. In fact, when reassigned, the name breathes life in another being.

Our Internet names must be unique to us. That uniqueness is essential to service providers. In addition, Internet names provide a means of recognition. Thus, short names in short supply help us to be recognized more easily. ${ }^{17}$ More than in real space the Internet name system deprives us of the freedom to use the names allocated to others. While people can have the same name and be distinguished by other means, the paucity of data about people on the Internet precludes such duplication. The name has become a major, if not the only, means of recognition. Shorter and special names have acquired greater value as a means of remembering and recognizing. Thus, short names have become the keys to Internet access as well as to finding each other.

Domain names are treated like property. They are sold even hypothecated. The source of these valuables is the one who allows their use - the one whose name allocation and name withdrawal will be respected by the other actors in the Internet infrastructure. Thus, name allocation and withdrawal are a source of power and wealth. Because the naming system is hierarchical, the managers of the system are also hierarchical, and so are their powers to allocate names. Since all names derive from one source, that source reigns supreme, and like the vassals in the feudal system, each vassal source derives it power from the one vassal above it, until it reaches the pinnacle - the king.

4.Enter ICANN. The Internet Corporation for Names and Numbers (ICANN) was established to achieve a number of objectives. First and foremost it should play its role in

15 To be sure, there are networks, and very large networks, that have different names, numbers and protocols. But if they are to interconnect with the global network they must fit within the naming, numbering, and protocols of the global Internet.

${ }^{16}$ In addition, there are services that do not actually transfer the messages but facilitate the search for particular sites on the Internet, such as America On-Line.

17 Although we view the Internet as a source of new and more information, much information, often the details, is lost on Internet communications. For example, we can receive information quickly from all over the globe. But information about the senders and receivers is more limited than in face-to-face, or even telephone, interaction. As one dog in front of the computer says to another in a cartoon in the New York Collection: "On the Internet, no one knows you're a dog." The New Yorker Collection. 1993. Peter Steiner from Cartoonbank.com. 
ensuring the stability and increased capacity of the Internet. It was also designed to increase the number of top level domain names and registries, to facilitate competition among the registries, ${ }^{18}$ and perhaps to help establish a dispute settlement mechanism between holders of domain names and holders of registered trademarks. ${ }^{19}$

ICANN can be viewed in many ways. It can be viewed as a forum for developing policy through a consensus. Or it can be viewed as a far more proactive manager of a technology-based market and a lawmaker. In this view it is designed to monitor and evaluate the infrastructure actors of the naming and numbering system, as well as the performance of the system. ICANN's lawmaking functions include allocation and regulation of some, though not all, lucrative infrastructure services, such as the functions of the registries and registrars. ${ }^{20}$ It also sets the qualifications of these actors. ${ }^{21}$ ICANN can therefore limit the entry into such businesses. Unlike governments, its mission is limited to its enterprise. The enterprise, however, affects many areas of human lives-business, culture, politics, community, public morals and private rights. Its reach is global. In that sense as well it is a lawmaker.

ICANN's structure is unique, and some say--unwieldy. It consists of a board, a President and staff, and three Support Organizations, the most problematic of which is the Domain Names Support Organization, or DNSO. ${ }^{22}$ Each such Organization nominates three board members while nine board members are to be elected by users. Elections by millions of people over the globe has not yet been achieved. Further, it is unclear whether

1818 Computer \& Internet Lawyer 31 (June, 2001) Current Development Domain Name ICANN Announces Decision On .com/.net.org Domains (describing the revised agreement between ICANN and the registry of .com, .org. and net, VeriSign, that had acquired the registry, Network Solution, Inc. was to be split, thus facilitating competition on the registry level); Sandra Dillich, Computer Dealer News (February 25, 2000) Network Solutions Loses .com, .net and .org; Industry Trend or Event(describing the negotiations that led to the agreement and the history and summary of the agreement).

19 See http://www.icannwatch.org/icann4beginners.php ICANN For Beginners; http://www.ntia.doc.gov/ntiahome/domainname/022098fedreg.htm (February 20, 1998) Improvement Of Technical Management Of Internet Names and Addresses; Proposed Rule (proposing a rule to improve the management of the Internet Domain Name System, and describing the infrastructure of the Internet). This rule was not passed. Instead the Department of Commerce issued a Statement of Policy in the form of a White Paper, which stated the main objectives contained in the proposed rule.

${ }^{20}$ Sandra Dillich, Computer Dealer News (February 25, 2000) Network Solutions Loses .com, .net and .org; Industry Trend or Event (noting the services that became "a huge revenue maker"). As to ISPs, aside from contracting with RIRs for some policy-making IP address block allocation, which involves little policy making, there are no qualifications or other regulation of ISPs.

${ }^{21}$ Saroja Ginshankar, InternetWeek (February 17, 1999) Internet Domain Name Registry Up For Bids. The monitoring and evaluation is to be determined by a committee of third parties. http://www.icann.org/minutes/prelim-report-04jun01.htm Preliminary Report Meeting of the ICANN Board in Stockholm (4 June 2001) p. 4 (“Whereas in resolution 01.60 the [ICANN] Board directed 'the President to prepare and present to the Board . . a proposal to form a committee to recommend processes for monitoring the implementation of the new TLDs and evaluating the new TLD program, including any ongoing adjustments of agreements with operators or sponsors of new TLDs.'”).

223 Domain Name Supporting Organization, http://www.icann.org/dnso/dnso.htm. DNSO structure does not contain a working group which deals with issues concerning the ccTLDs. 
ICANN was expected to establish policies or merely to approve policies established by its three Support Organizations. The DNSO did not succeed in reaching a consensus on proposed policies. ${ }^{23}$ In contrast, ICANN has been successful in gaining support on a number of fronts.

\section{PART TWO. THE INITIAL SOURCE OF POWER}

Two views, a positive and a negative, explain the creation of ICANN. The positive view describes ICANN's creation as the expression of a consensus on a specific agenda among parties with different interests and views. This description reflects market transactions in which the parties agree to enter into transactions on certain terms, even though they disagree, for example, on the wisdom of buying or selling. Had they agreed on this score there would have been no transactions.

The other view is more negative, but also consensus-based. The interested parties, such as the technical communities, the large business interests, Network Solutions, Inc., the various governments, the large ISPs, the small Internet ISPs, the small businesses that use the Internet, the various governments, had very different views of what the Internet infrastructure should be and how it should be managed. Most importantly, they disagreed on who should have the power to manage the naming system. Therefore, their consensus on the issues was reached at a very high level of generality. The devil of the details was left to be resolved.

The negative view of ICANN's power suggests that these parties with different interests have agreed not to claim control, if everyone else would not claim control. ICANN's power was therefore created by default. This aspect of the consensus reflects market transactions. While sellers and buyers on a market disagree on many things, including on whether it is desirable to buy or to sell, they agree to interact in the particular market. In the case of ICANN the parties agreed tentatively to a very tenuous market structure in order to continue to transact. To establish the market they had to agree not to demand control over it, because they knew that the other parties would not enter that market to transact. In this paper I focus on the agreement of this negative kind, creating ICANN's power by default.

1.Power by default. "I will not claim control, if you do not claim control." ICANN was created because no one interest group has agreed to put another interest group on the throne to manage and regulate the infrastructure of the Internet. This absence of agreement is demonstrated by the concern that permeated ICANN from its inception: it was concern about "capture" of control over the organization. It seemed as if, although no one interest group had ultimate control, every group was anxious about capture by another.

There were a number of candidates for the job: The United States and other governments, the established technical communities headed by Dr. Jon Postel, and the large businesses, the professionals who sought to participate in the infrastructure for profit, people who claimed to represent the consumers or users, and international communication organizations.

The United States, which triggered the emergence of the Internet, and the United States administration, which exercised the management power over the Internet, did not seek to continue hegemony over the Internet's infrastructure. The administration was

${ }^{23}$ See Part Four $\$ 3$ describing the disaffection of the ccTLDs registries. 
hard pressed by a number of countries to de-Americanize the Internet. Other difficult political issues have arisen, how to define a country, entitled to a ccTLD, and how to convert into competition the monopoly position of registries, notably Network Solutions, Inc. (now VeriSign) that managed .com, .org, and .net. The business communities had sometimes clashed with the technical communities' solutions that involved costs in dollars and time.

The United States administration was ready to offer the Internet to the world, but with strings attached. To de-Americanize the management and regulation of the Internet infrastructure without severing its American umbilical cord, the administration considered different avenues. Since the interested groups did not reach a consensus, the administration conducted meetings and produced a policy paper that seemed, at a high level, to represent a consensus not only within the United States groups but also with foreign governments.

While different governments demanded the de-Americanization of the Internet, none claimed to be the sole governor of the Internet infrastructure. It was recognized that none would succeed in realizing such a demand, and the only country which in fact controlled the infrastructure, namely the United States, was unlikely to relinquish the control to another country. Neither was the United Nations an acceptable alternative. The control over the Internet infrastructure required both guiding management and rule making. The United Nations and its various organizations were considered too slow and inflexible to respond to the fast changing demands of the Internet.

The technical community, especially IANA lead by Dr. Postel, was a natural candidate for the management of the infrastructure of the Internet. It had been managing the infrastructure since the Internet's inception. Many members of the communities were in fact the Internet Service Providers and registries. They also commanded support of some European governments. These communities wanted to undertake the management and regulatory function. However, the United States business community and Network Solutions, Inc. (NSI) (now VeriSign), the registry of .com, .org. and .net, and the manager of the root, did not agree to a transfer of control to the technical communities, and demanded a voice, even a decisive voice, in decisions concerning the Internet infrastructure. Therefore, a compromise between these two interest groups and their different visions of the Internet had to be reached before a private corporation could be established.

The conflict between the technical communities and the business communities was complicated because none is well described by their names. Members of the technical communities belonged and were employed by large business organizations such as MCI, AT\&T, and IBM. These persons, however, were members of the technical part of the large business organizations. They were also involved in the Internet service providing activities. Thus, not all parts of the business communities necessarily objected to influence of the technical groups.

On the other side of the coin were the registries, and especially NSI, Inc. that provided registration services but were publicly owned and operated as businesses rather than as volunteer or scientific enterprises. Thus, it would be more accurate to describe the conflict as a conflict between two philosophies. The one viewed the Internet as a tool for business development or as a source of profit from servicing. The other, rejecting the 
view of the Internet as a tool for "making money" viewed the Internet as the product of technological creativity to continue contribution to science and society.

The disagreement was not only between different interests but between different cultures and views of what the Internet was designed to do and whom it was designed to serve. Consequently, the technical communities could not assert control over the management of the infrastructure of the Internet. The added complications of political pressures made the choice of technology alone an inappropriate criterion for decisions about the infrastructure. It was no longer acceptable to pay little attention to the political and business consequences of technical decisions. The future body that would guide the infrastructure of the Internet had to consider all three criteria (technical, business and political), mediate among them and balance them correctly. This conclusion brought about the idea of an entirely new organization to meet these new demands.

The small business interests and those who claimed to represent the users were not candidates for control of the infrastructure, but demanded participation in the control. They, too, were divided not only among themselves but also in their loyalties. Some aligned with technical communities, and some with other clusters of interest, and many did not align with anyone.

The route to establishing the entity that would manage and regulate the Internet infrastructure was cloudy. The United States administration wished to avoid "establishing" and "controlling" a private corporation. Many such corporations have been created in the past, but under the law they had to be grounded in an Act of Congress. ${ }^{24}$ There was concern that if the matter came before Congress it would become a problematic "political football." To avoid the required Act the administration had to avoid the "establishment and control" of such a corporation. From the point of view of the administration and some members of Congress the solution was to help create a private corporation, grounded in market principles, and an Internet infrastructure moved by competition. This creation would be an entity that no one established, but just came into being. In fact, that is the closest description of the emergence of ICANN. At the same time, the cloudiness of its establishment indicates not one invisible hand but many invisible hands. That is because if only one hand as invisible as it might have been, had brought the entity into existence, other powerful hands, would have been raised in protest. The flurry of negotiations, promises, some broken, some re-negotiated, some abandoned, and alliances formed and reformed brought about an equilibrium that allowed the entity to emerge. The driving force of the negotiation and consensus seems to have been the recognition that no better alternative was available. ICANN was therefore born by default. ${ }^{25}$

${ }^{24}$ Under federal law, the executive branch may establish and control a private sector corporation only under a statute. See Government Corporation Control Act of 1945, recodified in 1982, 59 stat. 597; 31 U.S.C. 841, repealed and recodified P.L. 97-258, 31 U.S.C. 9101-9110. See also A. Michael Froomkin, "Reinventing the Government Corporation," 1995 U. Ill. L. Rev. 542. Arguably, because the executive did not "establish" nor "control" ICANN, the statute did not apply to it. ICANN has been operating on the basis of an agreement with the Department of Commerce. The Department of Commerce asserts its authority to enter into such agreements, but questions persist.

${ }^{25}$ Congress was merely appraised of the emergence of ICANN. The ccTLD registries are currently paying ICANN a fee for services that they used to receive from the U.S. government free. It was suggested that they are willing to do so in order to "pry the Internet naming system 
2.ICANN's initial power was weak. ICANN's power was not only vested by default; it was not a very powerful power either. The circumstances of its birth did not inspire unlimited confidence. ICANN was established without the blessing of an authorizing statute. ${ }^{26}$ Neither did ICANN benefit from the belief that its arrival was due to the invisible hand of the free market or the citizens' votes in a democratic regime. In fact, it emerged as a result of many negotiations among interest groups with the service of intermediaries.

In addition, ICANN's mandate was general, and some of its missions posed conflicts between technological, business and political views. It was required to allow additional generic domain names, while the largest corporations with the most famous brand names objected to any such addition because it imposed heavy costs on them in protecting their trademarks. ICANN was required to create competition among registries, and especially to break up NSI's monopoly. Yet that monopoly was in part based on the infrastructure of the Internet that required registries to maintain a central data base to avoid duplications of the names and the numbers. The "ownership" or other form of entitlement of the names and the databases were not established. To create competition among registries and registrars required portability of the names, and demand for names coupled with the vision of a free market in the names gave the names the features of property with attendant unanticipated consequences, such as cybersquatting. In sum, ICANN's management decisions could have far reaching consequences beyond its control, and at the same time conflict with the desires of one or more of its supporting interest groups.

ICANN received the mantle of Dr. Jon Postel as the manager of the naming and numbering system. But not quite. It did not have his authority nor the adoration of his followers, which have grown with twenty five years of his service and good judgment. It did, however, have a contract with the Department of Commerce, and a conditional contract at that. To become fully vested with the powers of the United States (whatever these are) over the systems, ICANN had to meet additional conditions under a certain deadline. $^{27}$

In sum, when ICANN emerged, its mission and power were not clearly defined. Its strength lay in the lack of better alternatives, in the highly reputable persons who populated its first board, and in a dedicated expert staff with significant knowledge of the Internet, its organizations and its history. This knowledge complemented the expertise of the board members, not all of whom were as knowledgeable. Needless to say, ICANN was not strong. The world sat back, folded its arms, and took a "wait-and-see" attitude.

ICANN was not powerless, however. It was backed by a number of power centers: the technical communities, the large business communities, including the large

from the U.S. government." Revolt Threatens ICANN'sBudget, USA Today Tech Report 2, http://www.usatoday.com/life/cyber/tech/cti821.htm

${ }^{26}$ Under federal law, the executive branch may establish and control a private sector corporation only under a statute. See Government Corporation Control Act of 1945, recodified in 1982, 59 stat. 597; 31 U.S.C. 841, repealed and recodified P.L. 97-258, 31 U.S.C. 9101-9110. See also A. Michael Froomkin, “Reinventing the Government Corporation," 1995 U. Ill. L. Rev. 542.

27 ICANN did not meet the requirements of the Department of Commerce and was therefore not fully vested with the authority over the root. However, the Department has averred its intention to make the transfer and retreated from a clear intent, at other times. The question of ICANN's legal status was discussed in a GAO report of 2000. 
Internet service providers, NSI, Inc. and the involved governments. This was ICANN's power base, and it was quite broad. ${ }^{28}$

\section{PART THREE. SOURCES AND AUGMENTATION OF POWER}

This Part lists the circumstances, actors, and methods by which ICANN has augmented its power.

1.Constitutional documents: the articles and bylaws. ICANN's articles and bylaws provide the entity with significant power. However, the entity's structure is also very complex, and the division of power among the different groups, such as the board on the one hand and the Supporting Organizations on the other hand, is not spelled out in the document. That is also because there was no clear consensus on the division of the power. Supporting organizations could designate their candidates to the board and could propose policies to the board. Although it seems to have been the consensus that the board could not reject the candidates it was not clear whether the board had to accept the policy proposals and whether the board could initiate its own proposals. It was also not clear whether initiation would be limited to non-technical policies, and whether one could distinguish between technical, political, and business considerations. Thus, the vagueness of the documents could provide ICANN with power, or rob it of power, depending on the implementation of its policies and solutions to the problems with which it would be presented.

2. The contracts with Internet service providers and registries. An important part of ICANN's power base is grounded in the contracts that ICANN negotiated with the Internet infrastructure operators, the registries and registrars. These contracts should rightly be added as part of ICANN's constitution. Said ICANN's president Mike Roberts: "ICANN had to take the very informal handshake world of [Internet founder] Jon Postel and turn that into language that can be written down and form the basis of a legal arrangement." ${ }^{, 29}$ ICANN sought to formalize both its relationship with the government and its relationship with the registries and the service providers through the mechanism of contracts. ${ }^{30}$

The contracts contain features that empower ICANN. For example, the party to the contract obligates the other party to abide by ICANN's policies, which are required to command consensus. A review board to be established has the authority to make a finding of the existence or absence of a consensus. The importance of these contracts cannot be exaggerated because the definition of policy decision is vague. Thus, so long as ICANN's policy decisions command a consensus they are binding on the signatories of the contracts, that is, on the actors in the Internet infrastructure.

Some economists have suggested the use of contracts as a response to the failures of the contestable markets theory especially in the deregulation period. "The ultimate objective is to replace transitory regulation with the contracts that would have been in

\footnotetext{
${ }^{28}$ This power base did not include recognized consumer representatives, except to the extent that national governments may be deemed to represent the interests of their citizens and residents.

${ }_{29}$ Maureen Sirhal, Net Governance: “.ICANN Makes Progress On Sticky Issue Of ; Domains, National Journal's Technology Daily, February 6, 2001. Such agreements have not yet materialized with most registries, let alone standardized; Maureen Sirhal, Net Governance: European Domains Want ICANN's Attention, National Journal's Technology Daily, December 7, 2000.

${ }^{30}$ Mark Sableman, ICANN Faces Major Challenge With Country Codes, National Law Journal, AT 4 December 18, 2000.
} 
effect had they not been superseded by regulatory institutions." 31 Therefore, lawmakers should negotiate laws in the market, and pass laws that are as close as possible to the negotiated result had there been a market. The visible regulators' hand should be led by the invisible hand. The contestable market theory and use of contracts are proposed as alternatives to heavy-handed inefficient government regulation. ICANN is using contract as a negotiated regulatory device. ${ }^{32}$

3. General support for ICANN's prime directive: to maintain the stability of the Internet. ICANN's directive has had the support of many, if not all, powerful stakeholders. Both governments and businesses that invest millions in Internet commerce and in persuading their customers to use this new medium put a very high premium on stability and operability of the Internet. Blackouts and other mishaps, even short lived, can cause heavy losses and terminate client relationships.

The prime directive of ICANN could be interpreted in different ways, some of which allow for more flexibility and experimentation than others. Many questions can be differently determined depending on this interpretation. For example, does stability require one root at all costs? Can a multitude of roots be designed in a way that would support stability and increased scope? Should experiments at the fringe of the Internet be encouraged, and if so, how can they be implemented once proven not to endanger the stability? Should these experiments be left to the market or be regulated? If experiments are allowed, to what extent, if any, should enterprises invested heavily in existing technology and structure have with respect to these experiments? Should these issues arise now, or should they be raised when the existing structure is well established?

ICANN has given a strict interpretation to the idea of stability, in line with the interpretation of its stakeholders and many governments. Consequently, ICANN chose to implement the prime directive by seeking to standardize the Internet infrastructure, allocating rights to Internet services and establishing the underlying policies. The interpretation of the prime directive as based on the current structure underlies ICANN's source of power. If only one root and no more than one root can exist, then it is difficult to imagine any other but a natural monopoly and its attendant power. Furthermore, the design of the naming and numbering system would, by definition, vest decision and lawmaking power in the manager of the system whereas any additional root would weaken or completely undermine this power. So long as the main stakeholders viewed the prime directive as crucial to their own interests ICANN must be endowed with sufficient power to implement it. That was and has remained a significant basis of ICANN's power.

4. A stable and able management. Before ICANN's inception Dr. Postel had capable legal advice of persons who understood power and its creation. They prepared its constitution, contracts and public statements. They later negotiated on ICANN's behalf. There is no doubt that ICANN's power as a lawmaker has been tremendously augmented by the services of this capable group of advisers.

5. Indirect help from Congressional action. Even though some members of Congress would have preferred to deal with Internet governance in a legislative capacity rather than a monitoring capacity, most members of the House committees that dealt with the

31 William B Tye, The Theory of Contestable Markets 121 (1990) (suggesting that contracts can be viewed as an extension of the Coase theorem).

32 Johnson and Post 
Internet were willing to take the "wait-and-see" attitude towards ICANN. However, whether by design or unwittingly, Congress has also acted in a way that made it possible for ICANN to perform a task that seemed impossibly conflicted. The performance of the task augmented ICANNs power.

One of ICANN's tasks involved the creation of additional gTLDs. ICANN was subject to significant pressure by those who sought greater competition among registries through the establishment of additional gTLDs. This requirement, however, was met with strong opposition of a large important stakeholder constituency of ICANN: the owners of famous trademarks. These large corporations have been spending resources to protect their trademarks and any additional gTLD may have meant enormous expenditures in protecting their trademarks.

Congress responded to this constituency in a way that reduced the objections of these trademark owners to ICANN's addition of gTLDs. Congress passed a law that protected famous trademarks from dilution, thus recognizing the trademark owners' right to the integrity of their trademarks. This was a fundamental change in trademark law, which was based on protection of consumers from confusion. ICANN established an option of less expensive resolution of disputes between trademark owners and domain name owners. The new statute, and the less costly process by which trademark owners could protect their trademarks against competing domain names reduced the objection of the large corporations to the creation of new gTLDs. Indirectly, and without addressing ICANN or its powers Congress has intentionally or unwittingly helped ICANN augment its power by performing its mandate, and this performance facilitated ICANN's exercise of power: allocating gTLDs, qualifying registries, contracting with these registries, and imposing on these registries the contractual obligations to follow ICANN's policies if backed by consensus.

Congressional monitoring has helped ICANN in two ways. First, it obtained accurate information, criticism, and a sense of the limits on its actions at least at that particular time. For example, when ICANN proposed to levy a \$1 charge on all registrars world-wide, for every domain name registration, the protest, which was aired also in Congress caused ICANN to back off. ${ }^{33}$ Some would consider this a failure. I would consider this event a success. When an entity has had no experience and its financing is uncertain, trial and error methods are not failures unless they are repeated. Congress helps ICANN evaluate its trial successes and errors.

6. Help from the courts. A recent decision regarding a domain name indirectly supports ICANN's power. This case does not involve a ccTLD but it does involve claims by a national government. The government of South Africa sued an enterprise in the United States maintaining that the enterprise used South Africa in its domain names. The South Africa government maintained that the name is its "property." The court denied jurisdiction and referred the parties to arbitration in accordance with ICANN's procedures. Both parts of the decision help maintain ICANN's power. One part is negative: courts are unlikely to entertain claims of sovereign powers to ccTLDs. The other part of the decision is positive. The decision as to the first part will be made in accordance with the process established by ICANN. It is also unlikely that any and all uses of a state's name will be barred by the arbitration tribunal. Thus, ICANN is likely to

${ }^{33}$ Mark Sableman, ICANN Faces Major Challenge With Country Codes, National Law Journal, December 18, 2000 
be free of making the difficult decision. Yet, the states' entitlement to the ccTLDs seems to be moving towards ICANN's domain if the parties seek an arbitration and the states do not demand full "ownership" over their Internet names.

7. Intermediation and negotiations among stakeholders. ICANN has chosen appropriate methods for consolidating power. Before decisions were made public, the governments involved were consulted and a consensus was obtained. Consultations have also been held with other large stakeholders. Only then would the results be published. Clearly because of these consensus building negotiations the freedom of the board to change its results after publication tended to be more limited. That is true of every prenegotiated consensus. However, by that time there was a sufficiently broad-based agreement and most decisions could be implemented. That is important when it is very difficult to obtain a broader consensus among many participants with different points of view and interests on defined specific issues.

Further, ICANN has not always insisted on exerting authority. Its dealings with governments are in the mode of negotiation rather than ruling. However, every agreement with any government helps build precedents for agreements with others, thereby helping to establish future customary rules. Moreover, when a conflict arose among powerful stakeholders ICANN was often inclined to play the role of a mediator rather than an arbitrator. It has provided an effective forum for negotiation and a face saving intermediary service. That increased its value to those participants. Repeat requests to ICANN augmented its power.

\section{PART FOUR. RISING POWER AND ITS BOUNDARIES}

ICANN's power has been on the rise as is demonstrated by recent events concerning country code Top Level Domain names (ccTLDs). Recently, ICANN has interacted with ccTLD registries and their governments. The context and substance of these interactions are very different, but all indicate the nature and level of ICANN's power. A number of reasons may have contributed to this rise. In addition, a case involving a government and a private enterprise points to shift of power to ICANN.

1.Country code Top Level Domain Names (ccTLDs). The ccTLDs are two letter names on the same level as generic Top Level Domain Names (gTLDs). Moreover, ccTLDs were designed to inform about the physical location of the name holders. With the rise of the value of generic TLDs, such as .com, the value of ccTLDs has risen as well. That is because under ccTLD one can create many new (and sometimes known) gTLDs under its umbrella. Country codes are similar to top level domain names except that they are limited to existing real entities, regardless of how we define them. ${ }^{34}$

CcTLD and their registries - delegates of the power to manage the database of the domain names under their authority--were recognized in different political units generously, when the value and importance of names and their management was not accompanied by political or economic values. ${ }^{35}$ For example, The Internet Assigned Numbers Authority (IANA), which preceded ICANN, recognized the delegation of a

\footnotetext{
${ }^{34}$ The argument of whether a country can assert exclusive right to its name was raised in a United States court. The court did not assert jurisdiction and suggested that the parties resort to the international arbitration system provided for disputes concerning domain names.

${ }^{35}$ http://www.dns.net/dnsrd/tld.html Top-Level Domains (describing ccTLDs and gTLDs and the controversies involving their delegation).
} 
ccTLD to Palestine, and thereafter confirmed a reassignment of the delegation to other registries. $^{36}$

The use of ccTLDs varies. In some countries they are used as generic categories. In other countries they represent a political geography. ${ }^{37}$ The United States government has considered privatizing the .US ccTLD ${ }^{38}$ but has not yet taken the decisive step.

2.The dispute over ccTLD .au between the registry and the Australian government. In 1986 Professor Robert Elz received from Dr. Jon Postel the delegated authority over the registry of Australia's ccTLD-.au. Even though the registry has the power to create second level domains, such as .com.au and .net.au, ${ }^{39}$ Professor Elz seems to have believed then and now that main Internet services should not be focused on commercial use. ${ }^{40}$ No commercial use meant also no value for the names. Consequently, "Australia has never had a cybersquatting problem like the United States has.",41

36 To avoid making a political decision, IANA followed a list by ISO 3166 Maintenance Agency, and agreed to the re-delegation of Palestine when Palestine was accorded the status of "Occupied Palestine Territory." http://www.icann.org/general/ps-report-22mar00.htm IANA Report on Request for Delegation of the .ps Top-Level Domain (22March 2000) (containing IANA's report and analysis which led to the recommendation to approve the re-delegation). See also http://www.din.de/gremien/nas/nabd/iso3166ma/ ISO 3166 Maintenance Agency (ISO 3166/MA) (12 June 2001); (describing the complete list of country names and ISO 3166-1 Alpha-2 code elements - the ISO country code used in the Internet).

37 http://www.isi.edu/in-notes/rfc1591.txt J. Postel, ISI, March, 1994 Domain Name System Structure and Delegation. Part of this description has changed with the years. The principles, however, remained the same. http://www.icann.org/icp/icp-1.htm Internet Corporation For Assigned Names And Numbers, Internet Assigned Numbers Authority (May 1999) (describing ICANN's practices in administering, and noting that IANA has remained the overall authority for day-to-day administration of the naming system, IP addresses, autonomous system numbers and TLDs, and other aspects of the system. The document includes the source where the "procedures to be followed in requesting TLD delegations or changes" can be found. The document contains the qualification requirements for TLD managers.).

38 http://www.ntia.doc.gov/ntiahome/domainname/usrfc2/comments.html The Digital Opportunity Trust: The DOT in .US (proposing an elaborate plan to manage .US for the benefit of all US citizens); Robert D. Lamb, Net Governance: Commerce Department Poised To Accept Bids For ; .us; , National Journal's Technology Daily, June 1, 2001. See Also, More On The .US Solicitation, ICANN Watch, http:/ / www.icannwatch.org/article.php?sid=208

39 http://www.phillipsfox.com.au/publications/Pncomm006.htm Reforms To Domain Name Regulation (June 20, 2001); http://australianit.news.com.au/print_page/0,2865,1551461,00.html Simon Hayes, Minister Backs New Domain Authority (December 26, 2000) (when Professor Elz was appointed he transferred the task of managing .au to Melbourne University. The university created Melbourne IT that issued securities listed on the Australian stock exchange).

40 It seems that Professor Elz controls more than the database containing the current domain name holders. ; see also http://it.mycareer.com.au/breaking/20010122/A15470-2001Jan22.html Kirsty Needham, Australian Government To Take Over Domain Names (January 22, 2001) (noting that the government agency bought a database of all domain names registered in Australia).

${ }^{41}$ http://www.smh.com.au/news/0106/13/biztech/biztech3.html Kirsty Needham, Internet's Reclusive Pioneer Hangs On To Keys To Web (June 13, 2001) 
The government of Australia, however, has different priorities, planning a far more aggressive development of the Internet. ${ }^{42}$ In general the government seems to prefer tighter government control of the Internet use in the country. ${ }^{43}$ It established an authority auDA, ${ }^{44}$ and required Professor Elz to re-delegate the registry's functions to this authority. The re-delegation of the .au space "will also automatically make auDA the arbiter of all sub-domains and give it the ability to delegate administrative rights for each of them." Professor Elz conditioned the re-delegation and it is unclear whether these conditions have been met. ${ }^{45}$ A year later, the re-delegation has still not taken place. ${ }^{46}$ In June 13, 2001 a news item stated: "Internet's reclusive pioneer hangs on to keys to Web." 47 Interestingly, he is deemed not to have responded to the government's request-"just not doing anything," rather than refused the request. The government views this distinction "relatively important.",48

The power relationship between a sovereign country, the registry of its name, and ICANN is unclear. ICANN and The Internet Assigned Numbers Authority published information in $1999,{ }^{49}$ yet the power relationship is being established by actions rather

42 http://www.phillipsfox.com.au/publications/Pncomm006.htm Reforms To Domain Name Regulation (June 20, 2001)

${ }^{43}$ http:// www.icannwatch.org/article.php?sid=197 AUDA Seeks ICANN's Help To Force .au Redelegation (June 6, 2001) (the Australian authority suggests that Professor Elz has been slow, but has not alleged any wrongdoing.

http:// www.thestandard.com.au/articles/article_print/0,1454,10175,00.html PeteYoung, Net Guru Ready To Pass The Baton, (July 28, 2000) (describing Professor Elz as an "Internet legend" and one of the "old guard" and reporting in July 28, 2000 that he may step down). This report has not materialized a year later. Id. (Professor Elz delegated non-exclusive registration rights in the .com.au to Melbourne IT but even though the company collected $\$ 93$ million in a public offering he refused compensation).

${ }^{44}$ http://thestandard.com.au/articles/article_print/0,1454,12158,00.html Pete Young, AuDA To Manage .au Domain (December 21, 2000)

${ }^{45}$ http://www.thestandard.com.au/articles/article_print/0,1454,10175,00.html Pete Young, Net Guru Ready To Pass The Baton, (July 28, 2000)

46 http://thestandard.com.au/articles/article.pint/0,1454,12158,00.html Pete Young, AuDA To Manage .au Domain (December 21, 2000) ("There are processes and precedents in place which allow the authority to be transferred without the consent of the delegated administrator but we don't want that to happen at all"). For a precedent by which IANA re-delegated a ccTLD of an island with the support of 48 out of its 50 residents, the two being the current delegate; Mark Sableman, ICANN Faces Major Challenge With Country Codes, National Law Journal, December 18,2000 . .

47 http://www.smh.com.au/news/0106/13/biztech/biztech3.html Kirsty Needham, Internet's Reclusive Pioneer Hangs On To Keys To Web, (June 13, 2001) (stating that Professor Elz "refused to relinquish his historic guardianship, flatly ignoring requests from the Federal Government to pass control of the country's Internet addressing system to a new regulatory body. . . The clash is one of the last stand-offs between the old school of the Internet and the commercial interests that now dominate it").

48 http://australianit.news.com.au/print_page/0,2865,2162,00.html Kate Mackenzie, Domain Standoff Tests ICANN, (June 21, 2001).

49 http://www.icann.org/icp/icp-1.htm Internet Corporation For Assigned Names And Numbers Internet Assigned Numbers Authority (On transfer and disputes over delegation of TLDs IANA should receive communications from both parties. It takes no action until the parties agree, noting that "it is far better when the parties can reach an agreement" because of the time it 
than by words and rules. Arguably a country should be entitled to its own name. The counter argument is that the name has been assigned by a private body and used by a private individual. Presumably it cannot be the property of a government. ${ }^{50}$ The entitlement to the names is a subject worthy of a separate paper. ${ }^{51}$ The important and interesting point for our purpose is the fact that the government of Australia approached ICANN for help. ${ }^{52}$ After all, Professor Elz is an Australian resident and perhaps citizen. The government could introduce a bill that would require the re-delegation. It may, perhaps impose by law a fine or use eminent domain over the ccTLD to requisition the name and appoint its own delegate. It took none of these steps. Instead it sought ICANN's intervention in the matter. ${ }^{53}$

3. The rebellion of the ccTLD registries. The registries of ccTLDs relate in various ways to the governments of the countries to which these ccTLDs provide access, and these differences are reflected in relationships between the ccTLD registries and ICANN.

A number of small countries have allowed registries for a fee to use their ccTLDs for commercial purposes, like gTLDs. ${ }^{54}$ These registries act and relate to the system as well as to ICANN as registries of gTLDs do. They have signed the contracts with ICANN as required, and pay registration fees. But these registries are a minuscule minority of the 240 ccTLD registries. The others, such as those serving France, Germany, and the United

would otherwise take and that" $[\mathrm{I}] \mathrm{t}$ is appropriate for interested parties to have a voice in the selection of the designated manager").

${ }^{50}$ http://australianit.news.com.au/print_page/0,2865,2162692,00.html Kate Mackenzie, Domain Standoff Tests ICANN (June 21, 2001)

51 See http://australianit.news.com.au/print_page/0,2865,2162692,00.html Kate Mackenzine, Domain Standoff Tests ICANN (June 21, 2001) (suggesting that sovereign countries should have control over their names and over the registries, but if the names are used as generic top level domain names, with the consent of the governments, the names should be treated as such, that is as gTLDs).

${ }^{52 h t t p: / / w w w . i c a n n w a t c h . o r g / i c a n n 4 b e g i n n e r s . p h p ~ K i r s t y ~ N e e d h a m, ~ I n t e r n e t ' s ~ R e c l u s i v e ~}$ Pioneer Hangs On To Keys To Web, (June 13, 2001) (stating the representative of the government "has written to the Internet's governing body, the International (sic.) Corporation for Assigned Names and Numbers, requesting his organization be recognized as the peak Internet body in Australia, not Mr. Elz"); http://australianit.news.com.au/print_page/0,2865,2162692,00.html Kate Mackenzie, Domain Standoff Tests ICANN (June 21, 2001) (noting that such an application is "virtually unprecedented," and that the other application for re-delegation involved Pitcairn Island). Id. (the unprecedented aspect of the case is that the delegate is refusing the redelegation).

${ }^{53}$ http://www.icannwatch.org/article.php?sid=197 ADUA Seeks ICANN's Help To Force .au Redelegation (June 6, 2001) (administrators of ccTLDs who have no been "designated managers" in the database of IANA have sought ICANN's re-delegation but were denied the request except for Canada); but what would prevent the government of the Ukraine from taking such steps if the registry were stationed in the Ukraine? See Julia Barton, Ukraine's Domain in Dot-Dispute, http://www.wired.com/news/politics/0,1283,44012,00.html.

${ }^{54}$ E.g., http://www.icann.org/general/pn-report-11feb00.htm IANA Report: Request Of The Pitcairn Island Council For Redelegation Of .pn Top-Level Domain (February 11, 2000) pn (Pitcairn Island); see also VeriSign Buzzes With The .bz Biz (ness), http://www.icannwtch.org/article.php?sid-185.

http://www.icannwatch.org/article.php?sid=185; NU Domain/IUS-N Mission, http://www.nunames.nu/about/about.cfm; What Is .tv? http://www.tv/en-defe9763cedc23f/en/about/about_company_overview.shtml?Hhtype=content 6/20/01. 
Kingdom, are generally designated by the governments of those countries, and the governments assert the right to re-delegate the management of the ccTLDs to others. Generally, as between the registries and the governments this is not an issue, and the registries consider themselves as an arm of their governments to further their governments' political and social policies.

Although these registries have been paying ICANN dues that cover about a third of ICANN's budget, many have not signed ICANN's contracts. Because they are not uniform in their functions and relationships to their governments, and because ICANN does not service all the registries, no standardized contract can be imposed on all of them. The text of these contracts has been negotiated for sometime, and a number of contract models have been developed for those registries that ICANN services, and those that it does not. ${ }^{55}$ In the process, ICANN has written to the governments concerning the registries, and this letter has raised the ire of the registries because some have interpreted the language to invite a review of the registries' performance. ${ }^{56}$ In sum, ICANN's relationship with many of these registries have not yet been formalized, and the task is formidable. ${ }^{57}$

Historically, ICANN has not made policy with respect to ccTLD registries and the registries were not actively involved in ICANN's affairs. This "hands off" approach by both sides seems to have evolved into a closer relationship. ICANN is seeking to formalize its relationship with these registries--establishing controlling measures over them--and the registries are aiming at a greater role in ICANN and its policy decision making. ${ }^{58}$ This is significant. The registries did not repudiate or question ICANN's authority. On the contrary. They demanded a greater voice in its power structure, that is, membership on its board. ${ }^{59}$

55 For a draft of a contract between ICANN and ccTLD registries. Sept. 2000 see http://wwww.wwtld.org/ongoing/icannservices/20001114.ccTLD-ICANN.service.html Draft Contract For Services Between ccTLD Managers And ICANN (November 13, 2000). For a draft of a proposed unsponsored TLD agreement with ICANN dated Sept. 21, 2001 see http://www.icann.com/tlds/agreements/unsponsored/registry-agmt-appn-26feb.01.htm Proposed Unsponsored TLD Agreement: Appendix N (February 26, 2001) For a discussion draft of ccTLD manager-ICANN "status quo" agreement see http://www.icann.org/yokohama/draftcctld-status-quo-agreement-05jul00.htm Discussion Draft of ccTLD Manager-ICANN “StatusQuo" Agreement; William New, Net Governance: "> ICANN Nears Deal On Country-Specific Domains, National Journal's Technology Daily, March 12, 2001. See Revolt Threatens ICANN's Budget, USA Today Tech Report, http://www.usatoday.com/life/cyber/tech/cti821.htm, 6/20/01

${ }^{56}$ http://www.icann.org/cctlds/draft-letter-to-govts-12nov00.htm Discussion Draft Of Letter To Governments Regarding ccTLD Managers (November 12, 2000); Mark Ward, Name Row Threatens The Net, http://news.bbc.co.uk/hi/english/sci/tech/newsid_1043000/1043509/stm

${ }^{57}$ Maureen Sirhal, Net Governance: "> ICANN Makes Progress On Sticky Issue Of ; Domains, National Journal's Technology Daily, February 6, 2001; Mark Sableman, ICANN Faces Major Challenge With Country Codes, National Law Journal, December 18, 2000.

58 Juliana Gruenwald, Domain Group Revolts Against ICANN, http://www.zdnet.com/zdnn/stolries/news/0, 4586, 2767690.html; Andrew Orlowski, Country Domain Cheifs Prefer JawJaw to War-War, http://www.theregister.co.uk/content/6/19712.html.

59 ICANN's relationship to the registry of us is unclear, as is the fate of the ccTLD. It likely, however, that whoever wins the bid on this ccTLD will have to conform to ICANN's policies. More On The us 
4.The statement of the United States Commerce Department. On June 25, 2001 the United States Department of Commerce responded to a request by Mr. William H. Bode on behalf of Atlantic Root Network, Inc. (Atlantic). Atlantic was concerned about the process by which ICANN has selected new top level domains. The response stated in part: ${ }^{60}$

In July 1998, the Department of Commerce made it clear that it would not participate in the selection process of new TLDs as set forth in the Statement of Policy, entitled Management of Internet Names and Addresses . . . In the Statement of Policy, the Department recognized that the selection of new TLDs should be conducted by the private sector through a not-for-profit organization, globally representative of the Internet stakeholder community. The Department recognized ICANN as that organization in November 1998 through a Memorandum of Understanding.

We note that at its May 2001 board of directors meeting, ICANN approved the establishment of a New TLD Evaluation Process Planning Task Force (Task Force) to monitor the implementation process and to evaluate the selection process of the new TLDs. The ICANN board resolution stated that the Task Force will make recommendations to the ICANN board and the Internet community regarding the selection process. It is our understanding that the Task Force will allow public input when formulating its recommendations. We encourage you to participate in this opportunity. In a recent letter to ICANN, the Department encouraged ICANN to move forward in the selection of new TLDs in order to increase competition in the domain name space.

Again, we encourage you to direct Atlantic Root Network's concern regarding ICANN's selection process directly to ICANN.

Sincerely,

(signed)

John F. Sopko

Acting Assistant Secretary for

Communication and Information

The letter speaks for itself, making it clear that ICANN has the support of the United States executive on this matter.

5. The three events demonstrate ICANN's power. The three events are different. One involves a dispute between a sovereign and a registry of its ccTLD. In the second situation the dispute is between registries of ccTLDs and The Domain Names Supporting Organization and ICANN. The third case represents a dispute between ICANN and an aspiring ccTLD registry, and demonstrates the United States government's position

Solicitation, http://www.icannwatch.org/article.php?sid-208; But see Brian Kahin, Making Policy By Solicitation: The Outsourcing Of us, July 162001 (suggesting that the winning contractor will determine policies and criticizing the current proposal to auction .us. While before 1999 IANA determined policy and Network Solutions, Inc. acted as a registry and performed the registration, after 1999, the policy function shifted to ICANN, NSI continued as a registry and registration became competitive, supervised by ICANN. It seems that under this plan, if ICANN is not the supervisor of the contract operator, it would be losing some of its hegemony).

${ }^{60}$ http:// www.icannwatch.org/article.php?sid=237\&mode=nested\&order=0 Commerce Depart: We Don't Do TLDs (July 8, 2001) 
respecting the selection of ccTLDs by ICANN. However, all three events demonstrate a recognition of ICANN's power to determine the existence and nature of ccTLDs, and the power to affect, at least by qualifications and imposition of fees, the identity and functions of the registries of these ccTLDs.

The Australian government applied to ICANN to determine its dispute with the existing registry of its ccTLD. ${ }^{61}$ Professor Elz may have implied ICANN's power to select or qualify registries because indirectly he based his rights on Jon Postel's appointment rather than on the appointment by his government.

The ccTLD registries felt that the Domain Name Supporting Organization, to which these registries belonged, did not represent the registries' interests. Therefore the registries left the Supporting Organization, but did not leave ICANN. Instead they demanded a more prominent place in its organization: a separate Supporting Organization and the right to appoint or select or recommend directors to its board. ${ }^{62}$ The registries were critical of ICANN's operating practices but not of ICANN "as an organization."63 The registries argued that there should be "no taxation without representation." 64 The use of these words is revealing. The power to tax is governmental; the right to representation is that of the citizen. It is unclear, however, whether the registries placed themselves in the position of citizens, and ICANN-in the position of a government. That is because the registries viewed their payments as fees for specific services and not as financing the operations of ICANN generally. But perhaps they only meant that if they financed ICANN's operations they ought to have a say about the way the money is spent. In any event, the registries recognized ICANN as the regulator of the ccTLDs both by explicitly mentioning their recognition and by demanding greater power in the organization.

The United States government was most explicit in its recognition of ICANN's power, rebuffing the aspiring registry, and encouraging it to apply to ICANN. It is not

${ }^{61}$ http:/ / www.Icannwatch.org/article.php?sid=197 AUDA Seeks ICANN's Help To Force .au Redelegation (June 6, 2001); http://thestandard.com.au/articles/article_print/0,1454,12158,00.html Pete Young, AuDA To Manage .au Domain (government agency's CEO stating that although there were other processes to allow the re-delegation, the government did not choose them).

${ }^{62}$ Laura Rohde, Defections At ICANN's Support Organizaiton, The Industry Standard.com, June 4, 2001; Laura Rohdle, Country Operators Defect From ICANN Support Org., Infoworld Daily News, June 4, 2001; Maureen Sirhal, Net Governance: European Domains Want ICANN's Attention, National Journal's Technology Daily, December 7, 2000. For the language of the registries' resolution see

http://www.wwtld.org/meeting/cctld/2001042`executive_summary.htm Executive Summary of ccTLD Stockholm Meeting on 31 May and 1 June 2001. Arguably, not all registries were of the same mind. Of the over 250 registries only 31 voted to make the demand and take the action. However, the others did not object nor abstain but simply did not take part in the process. See also Mark Ward, Name Row Threatens The Net, http://news.bbc.co.uk/hi/english/sci/tech/newsid-1043000/1043509.STM.

${ }^{63}$ Laura Rhode, Defections At ICANN's Support Organization, The Industry Standard.com, June 4, 2001

${ }^{64}$ Laura Rohde, Defections At ICANN's Support Organization, The Industry Standard.com, June 4, 2001; http://news.bbc.co.uk/hi/english/sci/tech/newsid_817000/817656.stm Mark, Ward, Net Groups In World Wide Wrangle (July 4, 2000) (the registries believe that the costs levied on them stem from legal costs of ICANN's dealing with Network Solution, Inc. and refuse to pay for costs over which they had no control). 
surprising that the only party which did not concede to ICANN's power was the aspiring rejected registry.

\section{PART FIVE. BOUNDARIES OF POWER}

The recognition of ICANN's power does not mean that its power regarding the ccTLDs is unlimited, or that the ccTLDs' registries are the same, or that they should be treated alike.

\section{A. CcTLDs example.}

1.CcTLDs differ in their relations to their governments and in their functions; some are similar and some are different from gTLDs. Governments do not treat their ccTLD registries alike. While Australia seems to desire a more government-controlled registry, the United States Department of Commerce has decided to put .us on the block. $^{65}$

Top level domain names can be any name born of our imagination. Otherwise, they are the same. Each must have one registry. That seems to suggest that the domain name owner has the right to choose the registry that would manage its name. As we noticed, some countries have in fact sold their name for commercial use. Others may use the registries to effectuate national policies, for example, encourage or discourage commerce through the Internet.

Enter ICANN. While ICANN has the power to recognize ccTLDs, I would assume that it does not have the power to eliminate those that were recognized and are used. It has the power to qualify registries for the purpose of ensuring the prime directive with which it has been entrusted. This power does not negate sovereignty. There are many cases in which governments are subject to constraints by other international rules grounded in the need for maintaining an international network. To be sure, these rules are usually imposed by an international body in which the countries are members. However, these bodies may also pass rules that bind the countries that objected to them.

A Request for Comments by Network Working Group authored by J Klensin, however, suggests that ICANN should "have as little involvement as possible in the direction of true country [code] domains." They should not be subject to ICANN regulation "beyond the basic principles . . . to ensure Internet interoperability and stability." Klensin states emphatically that these registries are different from the rest of ICANN and DNSO structures and believes that ICANN's "hands off" attitude would strengthen ICANN and avoid collision with sovereigns, the need to determine their legitimacy and the authority of their delegates. ${ }^{66}$

65 That decision, however, has not yet been implemented, and its implementation may await feedback from other governmental bodies http://www.icannwatch.org/article.php?sud=209 House Heavyweights Fire Warning Shot On .us (June 14, 2001) (describing the reaction of members of Congress and its request to slow down "until the underlying policies can properly be reviewed by the Administration and Congress). Department of Commerce request for public comment on domain names, Management And Administration of the .us Domain Space (August $22,2000)$.

${ }^{66}$ J. Klensin, Reflections On The DNS, RFC 1591, And Categories Of Domains at 5, http://www.isi.edu/in-notes/rfc3071.txt. See also Ua Dispute: Secret Police Seek Control Of Top-Level Domain, http://www.icannwatch.org/article.php?sid=215. The conflict is likely to be brought before IANA and finally ICANN); Julia Barton, Ukraine's Domain In Dot-Dispute, http://www.wired.com/news/politics/0,1283,44012,00.html. 
So long as most countries recognize the need for ICANN's services as managers and lawmakers, its selection of the ccTLDs and qualifying their registries are likely to be accepted by all countries. At the same time, it is likely that ICANN will not impose its rules on ccTLDs and their registries without assuring the consent of the affected governments, or perhaps all governments, if a precedent is involved. To the extent that the registries function within the boundaries of a country, they may need not be subject to ICANN, just as any intra-network, however large, is free of ICANN's dictates.

2. The status of ccTLD is unclear. Some argue that ccTLDs are property, and sovereign governments own their ccTLDs. By virtue of this ownership they have the right and power to appoint their own registries. Control by other bodies conflicts with the idea of sovereignty. Presumably, regardless of ICANN's or the United States' position, a government could use its domestic laws to assert ownership over the ccTLD representing its name, and to select and regulate the registry that manages the name. This argument gains strength when the registries for a country's ccTLD are placed outside the physical boundaries. $^{67}$ Not only is the country unable to control these registries, but they are subject to the physical control of other governments. ${ }^{68}$ There are arguments to the contrary. Registries of ccTLDs hold the power in trust for "the local Internet community." The government's decree is not necessarily and not always in the interest of the community. This is not the place to resolve the controversy. What is significant is that the government of Australia did not assert "ownership" but chose to resort to ICANN. Further, the registries of countries that stress their sovereign rights to their ccTLDs demanded participation in the management of ICANN.

3. ICANN's power to control ccTLDs and their registries. Arguably ICANN's claim for control of ccTLD registries is "inherently weak" as compared to its power regarding gTLDs. While ICANN's authority to establish and regulate gTLDs is grounded in its agreement with the United States government, some have argued that its claim to control the ccTLD registries is less founded absent any "normal perquisites for political power, such as treaties, pre-existing legitimacy, physical power or even broad recognition of need." 69

ICANN can base its claim on precedent: Dr. Postel's practice of assigning ccTLDs. This practice is continued and implemented on behalf of ICANN by the organization he had headed-IANA. But ICANN's position is fundamentally different from that of Dr. Postel's, in great part because domain names have been commercialized and their monetary value has rocketed. "Mr. Postel had been the Santa Claus of top-level domains: he created and gave away domain-names wealth. ICANN entered the scene to

\footnotetext{
67 Julia Barton, Ukraine's Domain In Dot-Dispute, http://www.wired.com/news/politics/0,1283,44012,00.html.

${ }^{68}$ With respect to the registries' rights see Best Practice Guidelines For ccTLD Managers (1 ${ }^{\text {st }}$ Draft) at 13, http://www.icann.org/cairo2000/centr-cctldbestpractices-24feb00.htm. First Draft of ICANN's Best Practice Guidelines for ccTLD Managers (stating that "No intellectual or other property rights in the 2-character code accrue to a ccTLD Manager as a result of the act of delegation of the responsibility for a ccTLD Registry").

69 Mark Sableman, ICANN Faces Major Challenge With Country Codes, National Law Journal, December 18, 2000; Julia Barton, Ukraine's Domain In Dot-Dispute, http://www.wired.com/news/ politics/0,1283,44012,00.html.
} 
take control of the goodies Mr. Postel had given out, and even to impose fees and obligations on the beneficiaries of Mr. Postel's gifts." 70

Arguably, if the existence of the ccTLD is derived from Dr. Postel's practices and from the directives of the United States government, his designation of the powers of ccTLDs registries should be followed. He described these powers as powers in trust for the nations and the global Internet community, to be exercised in a way "responsive to the culture of the country [bearing the ccTLD name]." ${ }^{71}$ These trust powers seem quite broad. Their vagueness may conflict with the specific provisions of ICANN's contracts and with the requirement that the registries follow ICANN's "consensus policies." But Dr. Postel had the same prime directive as ICANN's: to maintain the stability and integrity of the Internet. Shortly before his death, he recognized that times have changed. Therefore, ccLDs and their registries may require closer management of the names by a central authority.

In sum, by resorting to ICANN, no government, including the Australian government relinquishes all rights to its ccTLD or to selecting its registry. There seems to be a recognition, however, that these rights are subject to the prime directives guiding ICANN in the performance of its functions. If too many governments were dissatisfied with the directive or with the performance ICANN might not survive. However, the past three years have demonstrated ICANN's management sensitivity to the desires and needs of the governments. ICANN has also demonstrated skills in searching and finding the common denominator which provided a basis for consensus among them. So far, the power by default seems to have been maintained and deepened by precedents such as the three events described above.

\section{B. ICANN as a monopoly in a contestable market}

1.Contestable markets. The introduction to this paper describes the theory of contestable markets. ICANN's circumstances, from the day of birth to its third birthday, bring to mind this theory. Some of the theory's assertions can explain ICANN's status. In fact, the inadequacies of the theory in the markets context are less pronounced in the context of power, at least on a theoretical basis.

\section{The efficient management of the Internet naming and numbering structure} requires a monopolist I assume that the stability of the Internet requires the existence of a single root. I further assume that if the root is managed by more than one manager, the financial and social costs of the Internet would rise. Two cooks will spoil the broth. Therefore, the structure of the Internet naming and numbering system mandates a single manager--a natural monopolist. The question is whether this monopoly will result in excessive exercise of power, similar to excessive charges that a monopolist would impose on consumers.

3. The nature of the market for power. The market that is discussed here is the market for managing the single root. It is the market for power to manage and make laws regarding the numbering and naming system. While in the business market competitors seek rents represented mostly by money, the "rents" from the power of ICANN are varied, and include the ability of the powerholder to ensure the stability of the Internet

70 Mark Sableman, ICANN Faces Major Challenge With Country Codes, National Law Journal, December 18, 2000.

${ }^{71}$ Mark Sableman, ICANN Faces Major Challenge With Country Codes, National Law Journal, December 18, 2000. 
and the integrity of the naming and numbering system, and the technical integrity of the system, or maintain and expand the value of its investments in the current system as registry or ISP, or control the system for political reasons or protect one's trade markets by freezing or reducing the number of additional upper level domain names. Potential competitors may be interested in social benefits, and the stronger they are as potential competitors, the greater is ICANN's constraint on exercising its power in ways that conflict with these social benefits. These self-interested goals cannot be achieved unilaterally because the Internet is dependent on the support and actions of many others with other agendas (e.g., governments, legislatures, and servicers of various kinds). They must all agree to the management's edicts. By their consent to ICANN they can achieve their own self-interested objectives, at least to an acceptable degree. ${ }^{72}$ It is the management power and its lawmaking capabilities that are the product in this market. ${ }^{73}$

The powers for which there is a market in this case is twofold. One relates to particular actions in the exercise of management and law making- "specific power". The other is the power to takeover all the managerial and lawmaking activities - "general power." The management and lawmaking power are similar to firms that produce a number of related products. In the business arena such firms can cross subsidize their products and thereby defeat the ability of their competitors who are producing only one type of product from entering the market.

Arguably, like business corporations, ICANN can "cross-subsidize" one type of its powers by another type. For example, it can subsidize qualification requirements for other less stringent contract terms. However, many of ICANN's potential competitors, such as governments, are also multi-product firms. The difference between them and ICANN is in their institutional structure. While they may have limited powers outside their territories, they have more power within their territories. They too can subsidize one power product by another. Even service providers have some multi product capabilities and ability to cross-subsidize. Thus, ICANN's competitors seem to be stronger than oneproduct business competitors.

\section{The competitors that present a constraining force to the monopolist. The} contestable markets theory suggests that constraining competitors to the monopolist are those whose sunken costs are similar to that of the monopolist. Investment, or sunken costs for a general power, are the costs of establishing a broad supporting coalition to take over ICANN's general power or at least to create a credible threat of such a possible takeover. Thus, if the members of ICANN's current supporting coalition were dissatisfied

${ }^{72}$ ICANN's power and the power of money are similar. Both are a store of value through which other objectives can be achieved. In fact, these are two different aspects of freedom and coercion. It is important to note that the purpose for which power is held is not the topic here. Power like money can be obtained voluntarily, by consent from others, and usually in an exchange. Power, like money can also be obtained from others by violence and extortion. The use of money, however, is more limited than the use of power generally. Money can be used coercively if it is necessarily to obtain values (assets) which other persons want. The person who has bread and would not part with it except through money, has power over the hungry person. Yet this power is based on the possession of the bread, not the money.

${ }^{73}$ ICANN's power can be analogized to the power of other managers and the market for CEOs. They compete for the position of managers by obtaining the consent (or at least the passive nonintervention) of shareholders, nominators, existing top management, unions, and perhaps others that wield power in the corporation. Or they may only receive the support of the nominators. They do, however, have competitors. Their market is small, though not a monopoly. But it may be sufficiently small to resemble a contestable market. 
with the existing structure, and had sufficient power to establish a different entity, they would present a formidable threat to ICANN's existence, and could force it to restructure. Alternatively, if a coalition of other competitors was sufficiently strong to convince the actors in the Internet infrastructure to cease following ICANN's instruction and follow the new coalition, or their own single root or another naming system or a different management of more than one roots, the possibility and existence of such a coalition would deter ICANN from exercising any power in a way that would displease this coalition. These scenarios are extremely unlikely.

Another scenario which is unique to the Internet is possible addition of new names through existing ISPs. I consider this to be a threat of competitors of special power, not a general one. The competitors' investment or sunken costs in the market for specific power are the costs of establishing a coalition aimed at the specific power, or a credible threat to the exercise (or non-exercise) of that specific power. The sunken costs regarding such a coalition or power of a single entity are more likely. As in the case of the commercial markets, the market for power in which ICANN operates is populated by different actors with different entry costs. They may exert political power, form coalitions, or offer rich revenues. Their "sunken costs" may not be higher than ICANN's entry costs, or may be even lower, especially in the case of "special powers."

The exit costs of such competitors should be close to zero if the investments in sunken costs can be used elsewhere. However, once a power structure is established the very loss of the power is not a zero loss, even if the coalition can continue to exist and flex its muscle, for example, by entering ICANN's power structure. The investment in creating a competitor to ICANN may be high because the powerful interests that are potential competitors conflict and they would be successful only if they find a better way to complement their interests than the one found by ICANN. ${ }^{74}$ Otherwise, potential competitors would enter the market only if ICANN exerts a higher degree of power than they would together.

If ICANN does increase or extend its power, competitors may invest in entering the market to enjoy the benefits of the greater power until it will dilute by the mere existence of the competition. Then they will exit, as the exit costs are not high for them. For example, when ICANN proposed to charge each domain name owner $\$ 1$ through the registries, Congress called a hearing. ICANN withdrew the proposal. Congressional hearings on this issue were not held.

4.Differences between business and power markets. One difference between the business market and power market is that potential competitors can constrain ICANN's power exercise not only by threatening to assert their own claims to power but also by withdrawing their support of ICANN. A monopolist in the business market does not need the support of its competitors. A monopolist in the power market may need that support,

\footnotetext{
${ }^{74}$ While outsiders who wish to get into the ISP and registries business and increase the number of domain names may try and form such a coalition they will have to overcome the power of the governments and those who would oppose the extension and those who would be concerned about the stability of the Internet. Thus, it may well be that those who wish to enter the field with two roots will have higher costs than those who would wish to replace ICANN with one root only.
} 
and ICANN does need it. Withdrawal involves no direct cost to competitors, but it may be very costly if it undermines ICANN and produces a worse alternative. ${ }^{75}$

Further, while in the business market competitors threaten to offer a competing product, in the power market competitors can threaten to exert power with respect to one special "power product" rather than with respect to a "general power" that ICANN is exercising. If it attempts to exercise power that competitors deem to provide "higher rents," competitors may enter the market. They will enter only in the area requiring a low--or no-- investment (they already have the power), and where exit is costless (they will exercise the power elsewhere), while the benefit from entry provide high rents.

It is harder in the power market to calculate a quantifiable price in terms of power that a monopolist should "charge." Even in the business market this determination has raised a debate. In the power market one can only speculate.

The extent to which ICANN will exercise power is limited, among other things, by pressures from other power centers. The more and varied these power center are, the more optimal the exercise of the power is likely to be. To the extent that it accepts limits, ICANN's exercise of power should be viewed as equivalent to optimal power level, similar to the most efficient "price" that a monopolist can charge because of its natural advantages at producing more efficiently the desirable products. But to the extent that ICANN would exceed the limits (charges monopolistic prices) we may expect competitors, especially those whose investment in substituting for ICANN is not high (e.g., they have already a coalition at hand), or, more likely, when they have already the partial power necessary to become special power potential competitors.

One of the criticisms of the contestable market theory is that it does not account for the activities of other competitors. In the case of ICANN this possibility looms very large and must be considered. Thus, the cost of competitors' entry must include the cost, if any, of ensuring that other competitors will not find it worth their while to do the same, or that they will join to cooperate, not to compete, with each other. In addition, the power of potential competitors matters. If small competitors wish ICANN to exercise or refrain from exercising its power they must combine and threaten to enter the market or press the larger potential competitors (U.S. Congress, the European Union, The Department of Commerce) to intervene on their behalf by threatening to enter the market.

5. Cooperation among competitors. Cooperation among the competitors is crucial to the validity of the theory as applied to the power market. Unlike business markets, cooperation in this case is not prohibited but encouraged. In fact, it can be named consensus. The nature of consensus is not well defined because its determination is not precise as the number of votes is. Consensus need not apply to all issues at hand, but to select issues. Yet, if the coalition is not broad based, ICANN will experience pressures from the "outsiders" if its actions are sufficiently injurious to them. These outsiders will then press or negotiate with true competitors to change ICANN's use of power. Finally, ICANN must negotiate with some competitors while it can impose its rules on others, depending on the power base of the competitors.

ICANN's power position is distinguishable from that of a monopolist in the business markets: It's own "sunken costs" are high and continuing as compared to some

75 ICANN may refrain from exercising its power, for example, to establish additional domain names opening the doors to new businesses. Potential competitors may form coalitions to overcome the inaction, and ICANN may take steps to stymie their efforts. 
competitors and their existing coalitions for general and specific powers. The invisible restraining hand in the business market is replicated to a great extent in ICANN's power market.

There is another market situation, which is similar to ICANN's powers. One of its objectives is to ferment competition among registries and registrars. Arguably, if ICANN continues to have an effect on this growing market, its power will expand as well. I doubt, however, whether that will be the case. This situation is similar to the situation of a monopolist who has a highly competitive market of suppliers. The monopolist can increase its rents because the suppliers' competition will reduce their prices. In that case, however, potential competitors may wish to enter the market because the cost of the supplies will be lower for them as well. The monopolist will then have to reduce its prices further to maintain its monopoly. ICANN's increased power may attract more potential competitors. Whether the analogy goes as far as inducing ICANN to reduce the exercise of its power in order to ward off potential competitors is an open question. On the one hand, more power attracts more competitors. On the other hand, the investment in creating a substitute for ICANN is likely to increase as well. However, potential competitors for special power may be more attracted to compete. If they already have incurred the sunken costs (e.g., congressional power, or governmental power) they can exert more pressure in the areas of their strength. That may reduce ICANN's power in those areas.

Needless to say, if the system of one root is replaced or changed to allow for more than one master file (through cooperation or technology) ICANN's power will be threatened, unless it manages the other root as well. This situation is similar to any merger in which two CEOs must compete for the top spot or share the glory.

\section{CONCLUSION}

ICANN might provide a model (to follow or reject) for a unique institution. Its powers will cover the globe, unlimited to particular geographical area, as are the limits of political units. The limits on its powers are substantive-limited to particular functions in contrast to the powrer of political units: a global government for a particular purpose.

This institution would be unique in a number of ways: First, like ICANN's initial power, it will gain power neither from above--a recognized higher authority--nor from below-a recognized large group. Second, like ICANN, it will be operating in an extraordinary complex environment, dealing with different governments, business interests, ideologies, and cultures. We may, indeed, witness the need for such entities. Third, like ICANN's operations, its operations will be subject to a constantly changing technological environment. Anyone can develop a new technology, and there are powerful incentives to develop a new technology that can undermine current systems, such as the current naming and numbering regime allowing for the proliferation of names. Incentives of private sector for short term gains main, however, create conflicts with long term public interests, like maintaining the integrity of the system. Fourth, Like ICANN, it may be subject to pressures to expand its mandate and color its activities with sharper governmental hues. ${ }^{76}$ It may also be subject to counter pressures to limit its

\footnotetext{
${ }^{76}$ Amy Harmon, Survey About Accountability Online, The New York Times, at 1-2, July 10, 2001, http://www.nytimes.com/2001/07/10/technology/10Mark.html.
} 
activities and its policies to implementing the technical decisions as accepted by others such as the business communities and the national governments. ${ }^{77}$ The unknown will always loom large. In this unstable environment its strategies will have to be short-term and flexible, while at the same time pinned down to its prime directive.

ICANN's current environment does not allow for much inertia. Competitors may often change their agendas, personnel and coalitions. Problems may arise that have never arisen or been anticipated before. If this environment continues, ICANN may remain alert and open to change. However, ICANN might develop precedents. If it follows them consistently, then, over time, these precedents can gain support and acquire the authority and power of custom. "Path dependence" may create a more stable and less flexible environment. It may stifle innovations, and lead to inertia. A third possibility is that ICANN will develop stable processes for dealing with an unstable environment, changing agendas, different contact personnel, and unanticipated political and technological developments. It may develop a stable method of preparing its staff and board to function in such an unstable environment. ${ }^{78}$

The future of ICANN's own structure is uncertain. An organization subject to so many pressures in so many contexts can become a platform for negotiations with no core structure of its own. Or it can develop its structure by persistent precedents and flexible restructure. ICANN seems to have both paths still open, setting precedents and helping negotiate. Perhaps it can develop a mix of both. ICANN has not been completely shaped, as yet. Its powers have not settled at equilibrium. Perhaps it never will. Perhaps it never should. ICANN continues to "muddle through," creating and recreating its own shape.

ICANN can bring unanticipated new knowledge on power markets. There is an extensive literature about business organizations and markets, and how they complement each other and coexist. Separately and in combination they are efficient under different circumstances. The markets for power and their relationship to organizations have also been explored in the context of national regimes, for example the balance of power among the legislature, judiciary and executive in the United States. However, the market of international power has not been fully recognized nor thoroughly explored.

The market for ICANN's power is somewhat similar to its many counterpartorganizations, such as International Labor Organization, and Human Rights Commission.. Like them, the market for ICANN's power splits a discrete topic - the naming and numbering infrastructure system. Like them, it is important.

We can learn more about the power market in which ICANN operates. Those vying for power in this market could develop efficient monitoring methods, efficient negotiation processes, and efficient ways of reaching consensus. This market could develop effective enforcement mechanisms through dependence, reciprocity, and other means. We may learn when monitoring methods through the Internet are efficient, and when other means must be employed. We may discover when negotiations should be

\footnotetext{
${ }^{77}$ In fact, ICANN was expected to have a limited mandate and serve as a prototype. Rather than encourage the emergence of an overall "Internet governance" or "Government" a number of such entities could each undertake a discrete area and interact on decisions concerning various interests.

${ }^{78}$ For a book that offers manufacturing corporations a method of dealing with problems, see Wliyahu M. Goldratt, What is this thing called Theory of Constraints and how should it be implemented? (1990) (suggesting a question method to uncover problems, solutions and their source of problems, and monitor for constraints. Most importantly, the author offers methods by which constraints can be used to further the corporation's objectives).
} 
transparent and when they should be conducted behind closed doors. We may find out how to manage effective public meetings and organize efficient steering committees for the purpose of reaching consensus, airing conflicts, or establishing new coalitions. We may even start developing a theory of global power markets, and use ICANN to teach us. 